\title{
Metformin in Ovarian Cancer
}

\section{Chinmoy K Bose ${ }^{1^{*}}$ and Nirban Basu ${ }^{2}$}

${ }^{1}$ Department of Gynaecological Oncolgy \& Clinical Trial, Netaji Subhas Chandra Bose Cancer Research Institute, India

${ }^{2}$ Department of Gynaecological Oncolgy \& Clinical Trial, Calcutta Medical College, India

*Corresponding author: Chinmoy K Bose, Department of Gynaecological Oncolgy \& Clinical Trial, Netaji Subhas Chandra Bose Cancer Research Institute, Kolkata, India, Tel: 09830114880; E-mail: ckbose@hotmail.com

Rec date: September 30, 2015; Acc date: October 27, 2015; Pub date: November 4, 2015

Copyright: () 2015 Bose CK, et al. This is an open-access article distributed under the terms of the Creative Commons Attribution License, which permits unrestricted use, distribution, and reproduction in any medium, provided the original author and source are credited.

\begin{abstract}
Metformin after its discovery has found many wonders in many varied uses, poly cystic ovarian disease being already established one. It is now standard therapy in such condition. Many enchanting pathways are depicted leading to its many efficacies. In last decade its use in ovarian and other cancers is proposed. Before another such use is proved we can see the subject had grown bigger; hence a review seems to be worthwhile.
\end{abstract}

Keywords: Metfotmin; Ovarian cancer; AMPK; Stem cell

\section{Introduction}

Ovarian cancer has remained an enigma in abdominal tumours which shows no sign before it becomes too late to cure. Till date seventy percent of such cancer is diagnosed in late stage for any cure. This is partly because we know less about its causation. Many theories are proposed but exact cause is not found. Even it is not decided from where this tumour arises [1,2]. Epithelial ovarian cancer which constitute majority of such cancer is a hetergous entity where two types (I and II) are described While type I is less aggressive and RAS related type II is predominantly TP53 mediated [3]. Stem cell described in such cancer depends on markers of "stemness" such as CD44, CD133, CD117, ALDH1A1, and EpCAM. Whereas there are many attempts to see characteristics of such stem cell in relation to NGF and FSHR [4-6]. Some other are trying to look at the metabolic reprogramming of cancer and cancer stem cells driven by genetic alterations which could be therapeutically targeted [7]. In such attempt metformin Gotileb et al. First proposed metformin in ovarian cancer in a preclinical study. It will be worthwhile to take closer look in the chapter of metformin in ovarian cancer.

\section{Early development}

Though there are many works on metformin in polycystic ovarian cancer in UK the subject of metformin's role in ovarian cancer has hardly any taker here except what could be found is a recent literature review by one group from Manchester [8]. And an observational quality of life trial recruiting patient in a study of the safety, tolerability and efficacy of metabolic treatments of advanced nonspecific cancer (METRICS) under Dr Angus Dalgleish in Care Oncology Clinic at Harley Street, London. They are using Metformin with Atorvastatin, Doxycycline and Mebendazole. We will describe clinical trials later again.

Interestingly, epidemiologist Josie Evans and her group from Dundee University seem to be the pioneers of this subject working on it as early as 2005. They did a pilot observational study [9] to show that metformin may be associated with reduced risk of cancer in patients with type 2 diabetes and a biologically plausible mechanism exists. The article became most popular and is cited 1100 times till date. This was followed by a Canadian cross-sectional study [10] with same finding shown in recent one [11].

\section{AMPK and LKB1}

Metformin (N', N'-dimethylbiguanide) is an anti-hyperglycaemic drug commonly used for the management of type-2 diabetes. It works by reducing liver glucose production and increase of glucose uptake by reduced insulin resistance peripherally in the muscle. Metformin via $5^{\prime}$ adenosine monophosphate-activated protein kinase (AMPK) usually causes weight loss and reduced appetitenot weight gain and increased appetite. A recent breakthrough has found the upstream regulator of AMPK to be a protein kinase known as LKBlas was proposed by Evans et al. LKB1 is a well-recognised tumour suppressor. Activation of AMPK by metformin and exercise requires LKB1. Activation of the AMPK system by metformin inhibits growth of tumor cells through three different feedbacks; one positive and two negative pathways in a tissue-dependent manner. There is inhibition of mammalian target of rapamycin (mTOR) and fatty acid synthesis (FAS), but stimulation of the p53/p21 axis [12]. Other intermediary of mTOR (REDD1) and other pathways like cyclin D and FOXO3 are also described [13-15].

\section{Other Mechanism of Anti-proliferative Activity}

\section{Miscellaneous pathways}

Metformin has antitumor activity in monotherapy and also synergistically with other anticancer agents. Metformin stops proliferation of cell by by reducing the VEGF levelscontrolling neo vascularisation of tumour. At hormonal level it induces progesterone receptor thereby increasing the response to hormonal therapy [16]. glyoxalase I (GLO1), an enzyme that detoxifies methylglyoxal, is selectively overexpressed in the apoptosis-resistant cancer cells [17]. Metformin inhibits the expression of glyoxalase I, thus overcoming resistance to chemotherapy. It decreases in the concentration of human telomerase probably through the mTOR pathway. Metformin also reduces the activity of Akt and Erk kinases, key regulators of metabolism and progression of tumors. It abolished mTORC1 activation without over-stimulating Akt phosphorylation on Ser (473) 
and prevented mitogen-stimulated ERK activation in cancer cells [18]. It also inhibits the formation of metastases.

\section{Stem cell approach}

Metformin down regulates the expression of a cancer-stemness marker CD44 and other stemness markers, including Nanog, Oct-4, cMyc and, ALDH in these cancer cells [19]. Metformin significantly restricted the growth of ovarian cancer cell lines in vitro. This effect was additive with cisplatin. FACS analysis confirmed that metformin reduced $\operatorname{ALDH}(+)$ ovarian CSC [20]. Nevertheless, lot more to be detected before we know more about CSC and the CSC niche moleculogenetically and metabolically [21].

\section{Metformin and immune system}

Metformin is able to block the activation of NF- $\mathrm{B}$, resulting in diminished cytokine-induced endothelial cell adhesion molecule expression. It may lead to decreases in chronic macrophage infiltration into the adipocytes of type 2 diabetics as well as lower the damaging consequences of autoimmunity. It can modulate the immune system outside of its anti-proliferative effects. It causes a significant enhancement of memory CD8 T cells which cause better tumor regression [22].

\section{Clinical Scenario}

Much can be said, deduced and seen in preclinical studies but drug efficacy and safety is a totally different matter when trial on human produce results which are only to valuable for patients. Early preclinical studies started just after the epidemiological studies and was continuing till recent times with almost equivalent efficacy [23,24] prompting many in vivo experiments. Say for example; Metformin can induce apoptosis in OVCAR-3 and OVCAR- 4 cells by activating caspases 3/7, down-regulating Bcl-2 and Bcl-xL expression, and upregulating Bax and Bad expression [25]. The induction of apoptosis by metformin was also enhanced by cisplatin and combination of these drugs did not modulate the expression of Bcl-2 family proteins in OVCAR-3 cell line, whereas the effect was enhanced in OVCAR-4 cell line.

In vivo study where A2780 ovarian cancer cells were injected intraperitoneally in different mice model studying growth and metastasis along with cisplatin [26] and paclitaxel [27] also showed its efficacy.

Ronald Buckanovich of University of Michigan is recruiting for a phase II clinical trial (NCT01579812) using metformin as an anticancer stem cell agent in ovarian cancer patients. Patients who plan to receive primary surgical debulking will initiate metformin therapy prior to surgery and then continue after surgery along with chemotherapy. Patients who will be treated neoadjuvantly will initiate metformin with chemotherapy prior to surgery and then continue both metformin and chemotherapy after surgery. Tumor specimens will be acquired for all patients at the time of primary surgery. The primary objective of this study will be to determine if metformin improves the recurrence-free survival (RFS) of patients relative to historical controls. Secondary objectives of this study will be: (a) to compare the amount of CSC in primary tumor specimens in metformin treated patients versus matched controls from our tumor bank, (b) to determine if metformin improves overall survival relative to historical controls, (c) to confirm the safety of metformin in nondiabetic ovarian cancer patients, and (d) as laboratory studies indicate that metformin is most active in p53 mutant cells and p53 is mutated in $\sim 50 \%$ of ovarian cancers, we will assess whether response rates correlate with p53 mutation status.

Seiko Yamada, University of Chicago is ready to recruit in NCT02122185 trial. Here patients will receive metformin hydrochloride postoperatively twice daily and standard chemotherapy regimen for 6 courses. Treatment for metformin hydrochloride continues for up to 2 years in the absence of disease progression or unacceptable toxicity. Another two like studies which have not recruited yet are in Fox Chase Cancer and in Center University Medical Centre Groningen. However, results will not be apparent before 2018 .

\section{Future Scope}

At the end Professor Gotlieb of McGill University needs special mentioning who has some interesting revelation that establishes the chance of ramification of this subject and opens probable and newer enchanting routes of understanding of cause and path to cure in ovarian cancer. The organic cation transporter 1 (OCT1) experiment has shown. siRNA knockdown of OCT1 reduced sensitivity of epithelial ovarian cancer cells to metformin but interestingly, not to another biguanide, phenformin [27]. Drug uptake differences due to heterogeneity between primary human tumors with respect to OCT1 expression may raise doubt as to which one is the optimal biguanide.

\section{References}

1. Kurman RJ, Shih IeM (2010) The origin and pathogenesis of epithelial ovarian cancer: a proposed unifying theory. Am J Surg Pathol 34: 433-443.

2. Bose CK (2013) Anomalous endocrine feedback of peri-menopause in the etiology of type II ovarian cancer. Future Oncol 9: 1257-1261.

3. Hayano T, Yokota Y, Hosomichi K, Nakaoka H, Yoshihara K, et al. (2014) Molecular characterization of an intact p53 pathway subtype in highgrade serous ovarian cancer. PLoS One 9: e114491.

4. Tilly JL, Rueda BR (2008) Minireview: stem cell contribution to ovarian development, function, and disease. Endocrinology 149: 4307-4311.

5. Vera C, Tapia V, Vega M, Romero C (2014) Role of nerve growth factor and its TRKA receptor in normal ovarian and epithelial ovarian cancer angiogenesis. J Ovarian Res 7: 82.

6. Bose CK (2009) Neurotrophin in obstetrics and gynaecology. J Stem Cells 4: 217-227.

7. Viollet B, Guigas B, Sanz Garcia N, Leclerc J, Foretz M, et al. (2012) Cellular and molecular mechanisms of metformin: an overview. Clin Sci (Lond) 122: 253-270.

8. Sivalingam VN, Myers J, Nicholas S, Balen AH, Crosbie EJ4 (2014) Metformin in reproductive health, pregnancy and gynaecological cancer: established and emerging indications. Hum Reprod Update 20: 853-868.

9. Evans JM, Donnelly LA, Emslie-Smith AM, Alessi DR, Morris AD (2005) Metformin and reduced risk of cancer in diabetic patients. BMJ 330: 1304-1305.

10. Bowker SL, Pohar SL, Johnson JA (2006) A cross-sectional study of health-related quality of life deficits in individuals with comorbid diabetes and cancer. Health Qual Life Outcomes 4: 17.

11. Bodmer M, Becker C, Meier C, Jick SS, Meier CR (2011) Use of metformin and the risk of ovarian cancer: a case-control analysis. Gynecol Oncol 123: 200-204.

12. Hadad SM, Fleming S, Thompson AM (2008) Targeting AMPK: a new therapeutic opportunity in breast cancer. Crit Rev Oncol Hematol 67: 1-7.

13. Ben Sahra I, Regazzetti C, Robert G, Laurent K, Le Marchand-Brustel Y, et al. (2011) Metformin, independent of AMPK, induces mTOR 
inhibition and cell-cycle arrest through REDD1. Cancer Res 71 4366-4372.

14. Ben Sahra I, Laurent K, Loubat A, Giorgetti-Peraldi S, Colosetti P, et al. (2008) The antidiabetic drug metformin exerts an antitumoral effect in vitro and in vivo through a decrease of cyclin D level. Oncogene 27: 3576-3586.

15. Hu T, Chung YM, Guan M, Ma M, Ma J, et al. (2014) Reprogramming ovarian and breast cancer cells into non-cancerous cells by low-dose metformin or SN-38 through FOXO3 activation. Sci Rep 4: 5810.

16. Milewicz T, KiaÅ,ka M, MroziÅ,ska S, Ociepka A, Krzysiek J (2013) [Metformin--new treatment strategies for gynecologic neoplasms]. Przegl Lek 70: 81-84

17. Sakamoto H, Mashima T, Kizaki A, Dan S, Hashimoto Y, et al. (2000) Glyoxalase $\mathrm{I}$ is involved in resistance of human leukemia cells to antitumor agent-induced apoptosis. Blood 95: 3214-3218.

18. Soares HP, Ni Y, Kisfalvi K, Sinnett-Smith J, Rozengurt E (2013) Different patterns of Akt and ERK feedback activation in response to rapamycin, active-site mTOR inhibitors and metformin in pancreatic cancer cells. PLoS One 8: e57289.

19. Shank JJ, Yang K, Ghannam J, Cabrera L, Johnston CJ, et al. (2012) Metformin targets ovarian cancer stem cells in vitro and in vivo. Gynecol Oncol 127: 390-397.

20. Kim TH, Suh DH, Kim MK, Song YS4 (2014) Metformin against cancer stem cells through the modulation of energy metabolism: special considerations on ovarian cancer. Biomed Res Int 2014: 132702.
21. Gotlieb WH, Saumet J, Beauchamp MC, Gu J, Lau S, et al. (2008) In vitro metformin anti-neoplastic activity in epithelial ovarian cancer. Gynecol Oncol 110: 246-250.

22. Delmastro-Greenwood MM, Piganelli JD (2013) Changing the energy of an immune response. Am J Clin Exp Immunol 2: 30-54.

23. Rattan R, Giri S, Hartmann LC, Shridhar V (2011) Metformin attenuates ovarian cancer cell growth in an AMP-kinase dispensable manner. J Cell Mol Med 15: 166-178.

24. Yasmeen A, Beauchamp MC, Piura E, Segal E, Pollak M, et al. (2011) Induction of apoptosis by metformin in epithelial ovarian cancer: involvement of the Bcl-2 family proteins. Gynecol Oncol 121: 492-498.

25. Rattan R, Graham RP, Maguire JL, Giri S, Shridhar V (2011) Metformin suppresses ovarian cancer growth and metastasis with enhancement of cisplatin cytotoxicity in vivo. Neoplasia 13: 483-491.

26. Lengyel E, Litchfield LM, Mitra AK, Nieman KM, Mukherjee A, et al. (2015) Metformin inhibits ovarian cancer growth and increases sensitivity to paclitaxel in mouse models. Am J Obstet Gynecol 212: 479.e1-479e10.

27. Segal ED, Yasmeen A, Beauchamp MC, Rosenblatt J, Pollak M, et al. (2011) Relevance of the OCT transporter to the antineoplastic effect of biguanides. Biochem Biophys Res Commun 414: 694-699. 